\title{
Mayhem, Magic, Movement, and Methods: Teaching and Learning about Hearing and Listening
}

\author{
Tara Brabazon
}

This is an article about a course, but shadows a much wider history of online education, media literacies and sonic media.[1] Teaching research methods is difficult.[2] Students hate it. Staff tolerate it. Occasionally, there is a comrade or sister who demonstrates as much commitment to Marxist and feminist research methods as Paris Hilton does to shopping, but most of the time it is hard to summon enthusiasm. Students approach these often mandatory courses with the excitement of a dental appointment. Similarly, academic staff justify such courses as being good for students, like regular flossing.

I had a problem. I had to develop a Masters-level methods module in Media Studies that could be taught throughout the world to students fluent in many languages and derived from myriad disciplines and professional experiences. It had to be applicable and rigorous, flexible and committed, motivating and stimulating. I had few staff, fewer resources and no technical support. It was just me, a microphone, an overloaded hard drive and a slow, standardized and generic university portal. This paper explores what happened from this mayhem with methods. [3]

It is a truth of education that we teach the surprises. Through this process, I learnt how to transform hearing into listening[4] and surprise into an opportunity. From this teaching-led research project, I explore how teachers can use the dynamic and emerging literature on sonic media, auditory cultures and media literacy to not only rescue a method from mayhem, but create magic through the movement in ideas and application. When the Fast Capitalism of contemporary higher education slams into the slow processes of teaching research methods, the resultant contradictions are productive and revelatory.

\section{The Mayhem}

Scholarly discussions about social networking sites and the convenience of mobile media exhibit the enthusiasm of a labrador confronted by an open refrigerator door. What is required is a careful study of how university teaching and learning models operate in specific historical moments of digitization. Such an investigation is wider and deeper than what David Gauntlett described as a "vague recognition of the Internet and new digital media, as an 'add on' to the traditional media." [5] Forming a considered, mappable and trackable relationship between form and content - user generated contexts and user generated content - is a foundational task of curriculum design. It is much easier - and financially rewarding with research councils and teaching and learning committees - to isolate a change in educational technology and overlay a learning 'crisis' or 'revolution' from it. My concern is that teachers, theorists and educational managers place too much attention on technology in education, rather than education in technology. While William Merrin confirmed with a flourish that "the revolution has already taken place,"[6] it is increasingly difficult to pinpoint if - let alone when - the moment of change (revolution?) in educational media 'happened.'

These debates about 1.0 and 2.0, interactivity and participatory media, quality and standards, haunt most teachers 
as we construct curriculum. It is particularly the case in my field of media and cultural studies. Indeed, Robyn Quin reported that "the history of media education has been characterized by defensiveness." [7] There is often a reason for this hyper-reflexivity and conservativism. Not only is Media Studies labelled a Mickey Mouse subject in the United Kingdom, but I had a more localized and immediate problem. There had never been a successful Media Masters-level course at the University of Brighton. There were many reasons for the failure to connect aspiration, intent and delivery. A former Polytechnic, it celebrated creativity[8] rather than creative industries and high art rather than popular culture. I (just) managed to guide a new course, a Master of Arts in Creative Media, through validation, assembling a range of courses at the edge of the media studies paradigm, ensuring that the distance education and on-campus modes of learning were rigorous and integrated.

Twenty students joined us for the course from Gambia, Nigeria, Cameroon, the Slovak Republic, Greece, Cyprus, the United States, Belgium, Australia, Brazil and throughout the United Kingdom. The students were challenging, committed, inspirational and aspirational. The group spoke six different languages and came from a range of professions, including print and radio journalism, computer science, pharmacy, publishing, photography, education and public relations.

It is a fascinating course to teach but it faced many challenges after the validation battles were fought. The goal was to ensure that it could be offered on campus and off campus, both part-time and full-time and that it would weave into the diverse lives and aspirations of a multicultural, international, creative media community. As it was new and not amending or updating older models and modes of learning, all the transformations in hardware and software in the last few years were embedded into the methods and modes of teaching from the first day it was offered. We had the great gift of starting anew and building something different and productive. Participatory media platforms were not an 'add on,' but a central element in both curriculum design and assessment.

Educational technologies possess three functions: to provide a framework for the presentation of learning materials, to construct a matrix for the interaction between the learner and the information environment, and to configure a communicative space between learners and teachers. While it is easy in an era of digital convergence to align and conflate these roles - to combine presentation, engagement and communication into an asynchronous bundle - there are advantages in the development of literacy and the building of an information scaffold to slow and differentiate these functions. [9]

Practicing Media Research, the mandatory methods module, was a particular focus in considering how to configure and align media production, media dissemination and the activation of media literacy theories.[10] Teaching research methods, particularly in media and cultural studies, is complex. Invariably there is a conflict between humanities and social scientific models. The qualitative sociologists titter at the semioticians. Those wedded to focus groups cannot fathom the unrepresentative nature of oral history. Fieldwork researchers cannot grasp the intricacies of the archive and unobtrusive research methods. In a radically interdisciplinary environment, it is difficult to overcome intellectual inertia to move outside a very narrow palette of research methods from a home discipline.

This problem had surfaced in the undergraduate research methods module. The first year of my arrival at Brighton, I was present at the once-a-semester student feedback session - called a course board. The student representatives savaged the mandatory methods module. The critiques varied from the usual boredom and questionable relevance to a mismatch between learning methods and applying them in a dissertation. The complaints continued at length. It became much more than uncomfortable and could not be dismissed as students having an extended whine at their teachers. The key at moments like this is to listen. As a sample, three undergraduate students told me about their experiences. Alice was a second-year student and has just completed the methods module when she spoke to me. Melanie was a former student and student representative who had been active in the workforce for a year. Abi was a colleague of Melanie's who went straight into the MA program upon the completion of her degree. These comments about the undergraduate method module are startling in their honesty.

Alice: Perhaps it is not as explanatory and in depth as it should be. While the recommended readings are helpful, it would good to have things clarified a tad better in the lectures and have a wider range of lectures rather than very similar lectures. Just, you know, the lecturers being there to be available and answering questions rather than expecting everyone to know what they're talking about.

Mel: From what I remember it was kind of rushed. Um. Very rushed - not as in depth as I wanted it to be ... It was almost as if the lecturer thought that we were meant to know it already, which we didn't. Obviously like the lecturer had more experience than we did ... I know we had trouble with seminars and stuff where people didn't turn up.

Abi: I found it very poorly constructed. I don't think there was enough ... People got to thinking that they could assume 
what it was about so they didn't bother turning up because it was very dry and very sort of - it was hard to learn. You felt you could read it in a textbook but really you could be taught it and understand it better and use it. I think to put your own examples through it to apply it to your research. It was just like boring and you felt like you were back at school and it was just just just awful, if I'm honest.

Teachers manage and negotiate phrases like the student experience for validation procedures and quality assurance. Many of these voices and views are poured into already existing mechanisms that suit university branding and advertising as much as improving the learning experience. As the list of problems in the methods module progressed, I was aghast. My mouth was open with shock. Fortunately, my mind was open as well. As I approached the MA Creative Media, I was determined to find a method to teach methods that would note their critiques and help them learn.

I buried myself in three distinct research literatures: teaching research methods, media literacy theory and sonic media.[11] I had worked in these areas for a decade, but wanted to create new links between these paradigms, settling on a fully online mode of teaching and learning for methods. This would enable the program to move through space and time. Asynchronous media was an obvious choice, so students could return to the sessions as and when they needed them, beyond the conclusion of the module and through the writing of their dissertation. Distance education and on-campus students could liaise and communicate early in the semester, reducing the isolation of both groups.[12] It became important that this one module would be more than a module, but the start of a teaching-led research project to experiment with new strategies and methods for postgraduate education. Colleen Murrell realized that not only was there an important role for podcasting in "interactive journalism training," but that "there has still been very little serious research into its uses - both in industry and in academia." [13] Part of my role was to contribute to that research literature by testing new links between sonic media and education.

My plan started to form. I would use a sound-only platform. I would test the hypothesis that more media are not necessarily better media. These premises were an attempt to correct the tendency logged by Anthony Chan and Catherine McLoughlin: "Audio has traditionally been neglected and underused as a teaching and learning medium.”'[14] Individual staff members would introduce their research method and show students how it works in application rather than in abstraction.[15] The idea was that staff would present readings on a method, including an example of their own research using that method. This was a way to address the critique of the undergraduate methods module in terms of its relevance and applicability. It was a way to close the gap between understanding a research method and being able to move and apply it to a new project. Attendance would not be required. I would not extol or vilify podcasting, but think about new options and alternatives that emerge from a much longer history of sound in education. I would not revel in adding 2.0 to any random noun or adjective, but focus on the development of media literacy, which requires neither a designation nor an imperative for platform migration. Jack Maness stated that "Web 2.0 , essentially, is not a web of textual publication, but a web of multi-sensory communication." [16] Obviously Life 1.0 and Education 1.0 are also based on multi-sensory communication. However, my goal was to shape a pathway through difficult and abstract material. This was enacted by limiting the available sensory material, finding a match between learning outcomes, mode of delivery, and student interactivity. The goal was not interactivity for its own sake or to activate a banal comment culture. The imperative was the development of media literacy in a way that was contiguous, gradual, contemporary, passionate, and planned.

All seemed to be going well. All the other modules and courses had their study guides and readings ready to distribute. Staff were organized for the year, and I just started to relax and enjoy the idea of teaching this extraordinary group of people. However, my confidence was short-lived. While the course had proven its worth and success to even the most neo-liberal of managers, a problem exploded three days before the start of the Orientation Week. Unfortunately, the first year that the course ran was during a period of the restructuring of Media Studies at the University. 'Restructuring' is managerial shorthand for randomized change or an inverted Trotskyite vision of permanent revolution. This institutional instability was to unsettle the foundation of the MA.

Prior to the Orientation Week, at the very moment that students were arriving at Heathrow and Gatwick Airports from around the world, the person who was meant to be running this mandatory methods module in the MA was assigned another teaching responsibility. The following email was received at 5:38 P.M. on Thursday afternoon, before all the materials were due to be distributed the following Monday morning.

Sent: Thu 25/09/2008 17:38

To: Brabazon Tara

Subject: Can I ask your advice please? 
hi Tara,

\begin{abstract}
I have (as ever) some staffing issues to resolve - ***** is still off sick and one of her modules is now without a module leader. It's a module ${ }^{* * * * *}$ has some involvement with and has been module leader for in the past. He's willing to take it on again, but he'll need to 'lose' one of his other modules and the only one anyone else can realistically take on is the Research methods on the Media Masters. I was thinking that ${ }^{* * * * *}$ would be ideal for this as he already liaises closely with colleagues for the undergraduate research methods - and that maybe he could do so with your support and guidance as I know you've already been involved in getting contributions from people and helping with the sonic sessions (and no, I haven't forgotten that I owe you a session myself!) - what's your opinion as Course Leader?
\end{abstract}

thanks

This was a complete and utter nightmare. The person suggested by the manager not only had a full teaching load but was the academic who taught the undergraduate methods module that had caused the problems that I was trying to correct. This academic had also never taught via distance or online education in his career. The only solution was that I would have to take over coordinatorship of the module. We all know that the best courses take months and often years of preparation. In this situation, I had Thursday night, Friday, Saturday and Sunday to write the study guide, find reading materials, record the sonic sessions, create the portal, upload the materials, photocopy the study guide and collection of readings for distribution on Monday morning to the students and post them via courier to the distance-education scholars. With few staff and less time, I called in some favors from former PhD students who hastily produced three sessions. In a matter of days, I recorded four of my colleagues in Media Studies, recorded my sessions, mixed them all and photocopied from 5:45 A.M. through to 8:55 A.M. on the Monday morning to just - finish the materials in time for the students to collect. I had to work thirty six hours without a break over the weekend, with two printers churning out materials. The module was ready. While this managerial hiccup just before semester resulted in rushed and last-minute preparation, [17] I was buoyed by the year-long research I had conducted to ensure that the framing, platform selection and theoretical basis for the module were well-considered. The key was to determine how the execution of this plan was to be assessed.

\title{
2. The Method
}

Although the final execution and delivery of materials was not ideal, I had been thinking about, theorizing and planning the form of this module for some time, taking on board the critique of the way methods had been taught in the past and how to improve this delivery for not only the current cohort but a new community of international learners.[18] Practising Media Research, as it was called, would be flexible in delivery, personal, intimate and applicable. It would implement the lessons from the historic use of sound in education. Podcasts of lectures would not be the chosen option. As early as 1984, Durbridge stated that "As compared with a written text, the spoken word can influence both cognition (adding clarity and meaning) and motivation (by conveying directly a sense of the person creating those words)."[19] The complexity of tone and voice is captured in new ways. Daniel Power realized that, "The ability to adjust or modulate frequencies allows us to communicate in a correct and artistic way with words and sounds [through] ... the ability to adjust intonation, inflexion, phrasing, pacing, volume, loudness and timbre."[20] Similarly, Mark Lee and Anthony Chan in 2007 argued that "while audio is certainly not new as a teaching and learning medium, it has been neglected and underused in recent times." [21] Most portals and platforms still emphasize text rather than sound. Twitter is only the most recent example. But if there is a moment of and for audio-only media in education, then it is now. Sonic media is a low cost mode of delivery that enables staff and students to know each other in a new way. With new low cost devices and intuitive interfaces, it is often the infrastructural glueware that lags behind and reduces the effectiveness of sound. For example, the University of Brighton, like many institutions around the world, deploys a standard Blackboard interface. Therefore, it is a slow process to both upload and download sonic files, even for those with Broadband. This issue is a problem. I have students in Gambia as well as Greater London. The (temporary) solution for those with unstable and dial up connections is to send the sonic files on disc with their other print-based materials.

Sound has great capacity for education. It has personalized content, capturing all the advantages of radio, along with learner control of the place and time for engagement. Sonic media and auditory cultures unsettle subjective geographies. New relationships are formed between participants and locations through the shared intimacy of sonic 
media. However, the best use of podcasts or sonic sessions (my description of audio files without an RSS feed)[22] emerges if they are short, diverse, entertaining, and contemplative. A diversity of media can summon a diversity of learning styles. For distance education students, there is an opportunity for a different mode of academic delivery, with asynchronous learning being suitable for students separated by geography and time zones. They can share a sound and discussion portal which enables mixed media presentations and collaborative discussions.

Sonic media has been my platform of choice for over a decade. The Open University has always been a beacon and inspiration. They resisted recording and distributing lectures. Remembering their experience, I wanted to ensure that as our media has become more portable and permeable in our daily lives that I neither compress nor forget this educational history. Sound-only media are intimate and immediate, literally whispering into the ear of the listener. They can slot into - and accompany - daily life on a car stereo while taking children to school, exercising at the gym, or completing a daily commute. They are flexible, permeable and can integrate into the available time of our students, whether they are part-time or full-time. However, it creates a series of further problems in a cultural environment that - to cite Douglas Kahn - "pervasively privileges the eye over the ear.”[23] Would the students bother listening? The undergraduates had not attended the methods lecture and seminar. Would the postgraduate bother downloading the file and taking notes from the session? Would they post messages and upload images and sounds?

To improve the chances of success, I tracked earlier experiments in sound, sonic media and auditory cultures. It is, as Klaus Bruhn Jensen confirmed, "sound remains significantly under researched as a form of communication, as a modality of experience, and as a resource for cultural expression and social action."'[24] I started using 'sonic sessions' in 1995, with analog cassettes as a platform for sound and education. My goal was to create mobile learning experiences that could assist in the understanding of abstract or complex ideas. With the eyes at rest, sonic literacies could enable new relationships between form and content, signifier and signified. Like most of us, I have experimented with analog and digital recorders, a range of microphones, and put my faith for a few years in the iPod as both a recorder as much as a player of sound. However that was a transitory commitment. In the early 2000s, Brittain, Glowacki, Van Ittersum and Johnson attempted to use the iPod to record their sessions at Michigan's School of Dentistry.

From the beginning, we attempted to contain costs. Because the iPod would be a low-cost solution, we explored it first as an audio capture device. Students reported using iPods to record lectures, and a few students placed iPods with supplementary microphones on their desks in the front row of the lecture halls. This method produced unsatisfactory audio quality and was highly dependent on lecturer position.[25]

Students found the audio quality poor. At Michigan, they started to use an Apple PowerBooks G4. The quality improved, but technician's time was expensive. As with Michigan's case study, this early iPod experience - for most of us - was hampered not by portability and convenience, but by the quality of the recording. Since they wrote this important piece, the quality of portable recorders has increased enormously, and the skill to use them has reduced. I understand the attempt to use the iPod as player and recorder. Mobile popular music players have been integral to the public acceptance and consumption of particular platforms. The attraction of the iPod and MP3 players are clear: they integrate screen and sound. The ease of scrolling through a personal music collection means that hours can be spent satiated in an individual's greatest-hits collection. However, their use in education is more arbitrary and ambivalent.

There are many assumptions about students and their use of technology. Most of the conjecture is incorrect or unproven. For example, Carie Windham reported her attraction to the iPod and podcasting, while noting a lack of experience in more complex uses of the platform.

\footnotetext{
When you ask most students what they think of their iPods, they immediately mention the benefits of mobility and small size. But when you ask them how they might incorporate podcasting into a course, they draw a blank. The most common answer is the most obvious: offering course lectures or instructors' notes as an audio or video download. The problem for most students is that downloading a course lecture is often their first foray into the technology ... Just because a student totes an iPod on campus doesn't mean that the student is podcast-savvy.[26]
}

Use of a platform does not guarantee that it is deployed well. There are always issues to balance when teachers favor particular platforms, hardware and software. These decisions must be responsive to the learning outcomes of a curriculum. My interest is what happens to education when we make it location-independent, a digi-space of i-lectures, iPods and PowerPoint slides. To cut away sensory complexity and focus on sound and aural literacies through podcasts requires pedagogical expertise and experience in sonic media. Norquay confirmed that "writing for 
talk is different from the writing you do for print.' [27] There must be attention to voice, intonation, pauses, pitch and pace. The goal is to enact vocal variety and dynamism through rate, pace, volume, pitch, inflection and pause. This skill set in creating sonic media is different from lecturing, particularly the 'technique' tethered to reading headings off PowerPoint slides. Good audio-only presentations are highly scripted. A recorded voice is distinct from the vocal sounds heard in daily life. Effective lecturers have different skills to good broadcasters and effective podcasters. Good materials for the ear rarely emerge from a lecture theatre. Part of the ease with which lectures have been plucked from analog delivery and moved to audio streaming and RSS feeds is a misunderstanding of the value of a lecture as an analog educational location and the specific characteristics, benefits and weaknesses of sonic media.

The Open University is an innovator in the history of media education and the reasons for this success were realized by Gary Berg who stressed three nodes of innovation: high quality content, student support and a strong research base.[28] As a result of this nexus, media choices were made in relation to learning goals. The OU were international leaders in the development of a proto-digital sonic literacy. A.W. Bates, in reviewing the successes of the Open University,[29] showed the importance of media choice and selection in distance education, including the history of audio cassettes for OU courses. He stated that, "Audio cassettes are low costs; all students already have facilities at home; they are easy for academics to produce, and cheap and simple to distribute; students find them convenient to use; and, when designed properly, they encourage student activity."[30] This review of the analog environment has relevance when ascertaining the applicability of digital platform choices. The Open University selected audio cassettes because they were low cost, accessible, and able to be produced by academics without intervention from technicians, and convenient to use. In terms of educational design, lectures were noted as inappropriate in developing effective sound-based OU educational strategies. The key realization - then and now - is that the media selected for curriculum delivery must be determined by the student's home environment. Audio cassettes were cheap. Broadband, iPods and computers are not. But all three are reaching a point where assumptions of greater student-ownership can be made.

Careful thought is required when writing a curriculum, considering how to align diverse student cohorts with digitally convergent media to attain learning outcomes. Bates constructed a checklist to assist this process.

\section{Assessment of Educational Technology}

- Cost

- Learning effectiveness

- Availability to students

- User friendliness

- Place in the organizational environment

- Recognition of international technological inequalities

Bates, A.W.1993. “Technology for Distance Education: A 10-Year Perspective.” P. 243 in Key Issues in Open Learning - a Reader: An Anthology from the Journal 'Open learning' 1986-1992, edited by A. Tait. Harlow: Longman.

The goal in thinking about web-based education is to ensure that a mechanism for quality control and evaluation is present. The division between 'new' and 'old' media is deceptive. The deployment of Web 1.0 and 2.0 is part of this problem in universalizing the availability and applicability of the online environment in all its multiplicity, diversity and scale for all social groups. The educational imperative must not be the celebration of the new but the selection of effective media that is relevant to its environment. The key choice for teachers configuring curriculum is not analog versus digital, but synchronous versus asynchronous media. For distance education learners, timeshifting enhances the effectiveness of educational platforms.

Sharing audio and video texts has been part of the post-war history of educational technology.[31] Often this sharing was in real time and space. Sharing digital audio and video files online has been possible for a decade. But it is the symbolic power of the iPod specifically, rather than MP3 players more generally, that has brought not only sonic media but podcasting more centrally into the educational portfolio.[32] Important educational opportunities are available through the iPod. Podcasts are simple to produce and receive, and suitable for distance education. They also offer an intellectual opportunity for reflection on sonic media. The most effectively branded platform for educational podcasts is iTunes U. The arrival of the iPod Video, iTouch, iPhone and iPad also created the potential for video podcasts or vodcasts. However - and even with the prevalence of web cameras - they are more difficult to 
create than an audio podcast. Their added value for education is debatable. Future research in this area, assembling the best use of podcasts and vodcasts for distinct learning goals, would be valuable.

Initial leadership in iTunes $U$ was provided by elite universities, including Duke, Stanford and the University of Michigan, but smaller campuses have increased their international corporate visibility through this relationship. As an example, Stanford's podcasts are professionally produced and while some of the sonic quality is variable in the presentations themselves, the tracks are introduced, advertised and mixed in a standardized and effective way. Stanford had a model to follow and extend, building on the high profile deployment of iPods by Duke University. Famously, in August 2004, Duke distributed 20 GB iPods to 1600 first-year students. With enough space to store five thousand songs, it was preloaded with orientation content in both spoken and written form, alongside information about Duke's academic environment and student activities. It was a US\$500,000 investment from the University. The key element of the Duke story that is underplayed in the retelling is that the University also provided a Belkin bar microphone to attach to the iPod. From this early program, students used the microphone to record lectures and interviews for oral history and community media. Academics used this platform to disseminate class content, record class-based discussion and for file storage and transfer. The iPod was enfolded into curriculum as a fieldwork recording tool.

At the end of the first year, Duke released its evaluative report of the iPod experiment.

Initial planning for academic iPod use focused on audio playback; however, digital recording capabilities ultimately generated the highest level of student and faculty interest. Recording was the most widely used feature for academic purposes, with 60 percent of first-year students reporting using the iPod's recording ability for academic purposes.[33]

The significance of 'the Duke moment' in the history of sonic media in education was to recognize that much of the value of the unit was derived from the Belkin voice recorder. It meant that listening could - with technical ease - transform into recording. The 'what if' scenario is an intriguing one. If Duke had distributed the iPods without the microphone, then student behavior may have drifted into listening to music. Instead, there was a more malleable and integrated relationship between listening and recording, the iPod and curriculum. If Duke's 2004 and 2005 'experiment' is assessed in terms of the wider iPod-owning constituency, then it is clear that most users mobilize the platform for listening rather than the production of material. Duke's story is different because from the start of the unit's distribution with a microphone there was an assumption of interactive production.

After two years of experimentation, the University moved away from providing iPods to students. [34] The iPod was treated, not as a branding or marketing device, not as a Web 2.0 platform and the basis of social networking and collaboration, but as "as a course supply, much like a textbook." [35] In the space of two years, iPods went from the forefront of educational innovation to the basic kit of an undergraduate student. In reviewing this short history, three strategies emerged for the iPod's deployment in education:

- distribution of lectures for review

- delivery of new educational materials (which may be termed 'supplemental materials')

- $\quad$ use for student assignments[36]

A diversity of materials is distributed through podcasts, even though the lecture dominates. Lecture recording is the simplest and least time consuming way to create sonic material. It may not be the most useful in terms of attaining learning outcomes.

In general, it is safe to say that most students do not listen to each and every lecture podcast. Only $20 \%$ of students in the UW study listened to more than $75 \%$ of recorded lectures. In addition to picking and choosing which lectures to review, many students also scan the lectures, fast-forwarding to specific points or sections, and listening to particular portions multiple times.[37]

Simply because lectures are syndicated to a student does not mean they are heard. Such a practice may also encourage a disconnection from curriculum. This problem was of concern within the preparation of my MA methods module -- and may have repeated some of the issues emerging in the undergraduate degree. Most students did not come to sessions and then complained that they did not have the knowledge they needed for their dissertation. Still, in international education, a series of surprises have emerged in how students work with podcasts. Most significantly, up to $80 \%$ listen to podcasts at their computer rather than deploying the mobility of the MP3 player and iPod.[38] The potential of mobile education - delivering content anywhere and anytime - is not revealed in the lived learning 
experience of students.

The advantages in persisting with these experiments through the challenges and surprises are enormous, as sonic media can offer a reflexive space for the teaching of abstract ideas. [39] But not every subject is best taught or learnt through digitized, mobile sound. When written and targeted for particular courses, approaches and student communities, the effects of sound in and on learning are powerful. For Practising Media Research, I wanted to both understand and differentiate between the longer sonic sessions I was producing and simply recording a lecture. The distinctions were clear.

\begin{tabular}{|l|l|}
\hline Characteristics of a Recorded Lecture & Characteristics of a Sonic Session \\
\hline Written for multi-sensory delivery & Written for a sound-only delivery \\
\hline Written for multi-textual literacy engagement & Written to use auditory literacies in isolation \\
\hline Length of session determined by the timetable & Length of session determined by content \\
\hline Sound quality variable & Control over sound quality and standardized production \\
\hline Lecturer concentrating on the many variables in a classroom & $\begin{array}{l}\text { Academic presenter concentrating on the singular aspect of } \\
\text { delivering high quality sonic content }\end{array}$ \\
\hline $\begin{array}{l}\text { Students must attend the session in the mode prescribed by the } \\
\text { timetable }\end{array}$ & Students can insert the session into their timetable \\
\hline
\end{tabular}

In my earlier research on the iPod and/in education, I stressed the ease with which staff could use the iPod's microphone attachment and record material of reasonable quality.[40] "Reasonable" was probably an accurate description in 2006, but sonic media platforms and editing software have improved and evaluative mechanisms (particularly from the corporate branding of podcasts) have also sharpened, demanding a higher quality of sound. Students can still deploy the iPod as a listening platform and use it to complete assessments, but better recording and editing is possible and necessary from staff. If Media Studies is to offer an intervention and interrogation of Web 2.0, then it is through the recognition that a domestication of media production rarely produces professional results. [41] In the early to mid-2000s, the iPod was able to create recordings that were quick and easy to disseminate, but now it is possible - at reasonable cost - for academics to develop and record higher quality materials.

We are now in a post-iPod moment for sonic media.[42] As early as 2006, Meng tracked the problems in the educational use of this convenient - if domestic - recorder.

Higher quality audio or video generally require a higher level of technical expertise. Currently many podcasts are known for their 'scratchy' or homemade personalities. As the popularity of podcasting grows we will see ever more sophisticated broadcasts with increasing production values and higher level of required technical skills. The School of Journalism at

The University of Missouri has already committed to producing all future podcast and vodcasts using 'best practices' - a professional quality level for their podcasts and vodcasts which they are currently defining.[43]

While Meng was clear in 2006 that sonic quality was re-entering the discussion, some theorists argue that the sound quality of podcasts was not important. For example, Anthony Chan and Catherine McLoughlin in the same year as Meng stated that,

The ability to produce high fidelity sound does not appear to be critical to the success of educational podcasts. Students tend to be quite tolerant in this regard, so long as the speech is sufficiently audible and clear. With this in mind, there is no need for sophisticated, studio-grade sound recording/editing hardware and software. To date, the project has relied solely on inexpensive, handheld computer microphones and free/open source software.[44]

It would be informative to ask if Chan and McLoughlin's students are still 'tolerant.' Other students have been less satisfied. Significantly, one equated a lack of quality in the technical output with a lack of commitment to teaching.

A novice podcast listener can tell the difference between poor sound and sound that reflects even a small amount of attention to detail and quality. For students to value a podcast, they need to believe that the professor values it as well. Part of that comes from demonstrating a commitment to quality in recording.[45]

Podcasts do not have to sound like the opening to Rick Wakeman's Journey to the Centre of the Earth. However 
technical and pedagogical expertise must be aligned.

Through the celebrations of social networking and user-generated content, quality, professionalism and technical expertise are re-entering the evaluative criteria. It is here that Media Studies scholars can offer international leadership, not through celebrating the iPod but recognizing the significant moment of disruption the platform caused, providing an opportunity to reconsider the role of sound in education. While academics from other disciplines and paradigms may find the lower quality recordings sufficient for their purposes, Media Studies scholars have an opportunity, through teaching-led research, to find new platforms, methods and options. As Colleen Murrell realized,

Academics may also baulk at the technological demands on their time. Preparing interesting and relevant podcasts does eat up the hours and so may not appeal to all lecturers as they juggle heavy workloads and the competing demands of teaching, research and administration. However, media lecturers may see the equation differently as they tend to be more interested than most in keeping up with technological change.[46]

While this last five years in educational technology may be termed an 'iPod moment,' actually students did not use it as a listening platform, and academics are moving away from the iPod as a recording device. The iPod is the symbol and activator of change, not the platform for change.

One of the services that can be enacted to educators by Media Studies scholars is to scaffold, structure and assist this movement away from the iPod. Its use as a mobile platform is clear. But its role as a recorder is limited. Its quality is reasonable for student work and software can clean up the sound, but reasonably cheap and powerful stereo recorders are now available. A flexible and useful recorder for a diversity of environments is the Zoom H2 Handy Recorder and its subsequent model the Zoom H4n. The Zoom H2 weighs 120 grams, has a power adapter and can use two AA standard batteries. It deploys a USB interface, permitting high quality recording with control over sound capture with four separate microphone capsules. Both models are inexpensive, intuitive and mobile. Yet even with the permeation of such hardware, the quality of material being released publically is still mixed. There is confusion between the availability of better hardware and software and the literacy and technical competency to deploy them well.

Concurrently, editing software has also improved for podcasts and the construction of sonic files. While Audacity is free, open source software - for which I have enormous respect - it requires the installation of a LAME MP3 encoder to overcome software patents. It is not as intuitive as other recording and editing programs. While the Adobe Audition III - which now enfolds the Cool Edit Pro editing suite - is arguably the best software on the market, its complexity and scale is beyond what is required for many educational productions. A more appropriate and available software at one tenth the price is Acoustica's Mixcraft 4, which is an intuitive multi-track audio recorder and remixer. Magix Music Maker 15, along with their Soundpool collection, is another low cost option. While useful for musicians and remixers, it is also ideal for constructing podcasts and sonic material, composed of perhaps two or three sound tracks. It allows a simple mix down into MP3 files. There are also new opportunities for convergence of both sound and vision, beyond the static vodcast. For example, Magix PhotoStory can allow the importing of MP3s such as oral history testimonies or voiceovers to accompany a series of captioned images. This simple program permits not only a considered discussion of the relationship between sound and vision but a significant archive of photography with either existing or created sound. Digital storytelling and the creation of rich digital data is also possible through deploying Flip cameras and Magix's Movie Maker. These are only two examples of hardware and software that are contributing to an expanding and dynamic space for sound-only platforms in education.

Sound is a mode of communication that slows the interpretation of words and ideas, heightens awareness of an environment and encourages quiet interiority. It punctuates buildings, workplaces, leisure complexes and family life. The visual bias in theories of truth and authenticity means that sounds are often decentered or silenced in empowered knowledge systems. Education rarely manages this sonic sophistication. Formal educational structures are geared to developing literacies in manageable print. Too often, teachers cheapen soundscapes with a monotonic verbal delivery of lectures, interspersed with stammering and confusion, and do not open our ears to the other rhythms, melodies, intonations and textures in the sonic palette. The i-lecture, which was subsequently rebranded Lectopia, was an example of how an urgent - yet undertheorized - need to gather 'online materials' from academic staff resulted in low quality sonic resources. The system was developed so that it could be automated and not reliant on academics 'ruining' the recording and distribution. This desire for standardization rather than standards has marginalized the complex relationship between media and education.

In 1995, the first mode of sonic sessions I recorded was on analog cassette was a short introduction to a week's teaching. It was a way to orient students into the material. The goal, particularly for first years, was to use a sound- 
only platform to interrupt their everyday experiences and prepare them for more formal, disciplinary literacies involving the encoding and decoding of text. In MA teaching, I use sound in more diverse ways. Firstly, it has a role to orient students into postgraduate education, making them aware of expectations and levels and standards of reading and writing. Secondly, sonic media provide alternative platforms to express information, defamiliarizing the relationship between signifier and signifier, to provide assistance for students facing print-based challenges or who are working in diverse languages.

An imperative of my use of sound for fifteen years has been to avoid replicating either analog lectures or seminars. I believe in the physicality of education, the importance of a group of people gathering in real time and space. I believe in the importance of gestures, expressions and nonverbal communication that are not applicable with sonic media. Obviously, sonic media have disadvantages, and the key is to use it selectively to boost its strengths and also to minimize the consequences of its blindness. Throughout my work with online education, I have never recorded - or believed in recording - lectures. Writing text for the ear and text for a multi-sensory synchronous lecture and seminar are two different modes of expression. Therefore, the challenge for me was to find a way to configure and extend the sonic session I had used for over a decade. I required a larger sonic space - between 1830 minutes in length - for a long session that was not a lecture. Much of the success has been due to the research, preparation and writing of the session, along with the mode of delivery and voice of the academics.

None of the staff involved in Practising Media Research had conducted online learning or distance education before this session. Therefore, professional development for staff - through one to one discussion and modeling was a priority.[47]

Julie Doyle: I currently teach an MA module Mediating the Environment which is presented, it's not online. And now I feel not only more confident but I see the benefits of being able to deliver teaching through an online medium because it means more people can take part in this learning and teaching process. So, I would, it's definitely had an impact on my teaching in terms of thinking about turning one of my existing modules which is on-site into distance learning. And also just thinking about, in my own research as well, talking about criticizing the visual, actually using a sonic medium, an online medium, made me think about ways in which I can actually use that medium in my own research and also my own teaching a lot more.[48]

Dr Doyle is research active and completing her first book. But this method of professional development was - and continues to be - important for research inactive staff to gain assistance in reconnecting teaching and research, and reconnecting with the international scholarly community. While bringing research inactive and early career researchers to increased productivity were incidental benefits of creating this new module, Practising Media Research did become a portal for teaching-led research and professional development for staff. It brought them to the early stages of writing and moved them into research activity. Significantly, staff only had to offer one week on their specialism. Therefore, they did not have the burden of delivering a new, full, online Masters module, but could attempt a combination of a known area of research interest on an unknown platform and in a new teaching mode. Certainly new modes of thinking emerged from this model of learning, encouraging the theorization of alternatives.

The other key principle besides not replicating a lecture structure that I carried forward in the construction of this module was to slow the learning experience. Obviously, accelerated, expedited, contracted, applied and workled learning has come to dominate our universities. As early as 1990, Alvin Toffler realized that "the metabolism of knowledge is moving faster." [49] John Tomlinson confirmed that "acceleration rather than deceleration has been the constant leitmotiv of cultural modernity." [50] Indeed, it now appears that Virillio's "city of the instant"[51] houses our universities. My intention through this model of teaching methods was to intervene in the speed of data extraction and just-in-time learning to ensure that students slowed their engagement with ideas. If they did not listen to the session, then they could not gather enough information to understand the readings or participate in the online forum,[52] which became the spine of social and intellectual engagements for the first semester of the course. Over 800 posts on the forum were made through the semester in which the module first operated. By releasing the content more slowly, at a pace directed by the student, the module's presentation of methods started to weave through their other modules and interests.

Speed is integral to how we understand industrialization, globalization, modernity and knowledge. Much of education is based on taking ideas and moving them around space and through time. The dominant media of an era is often the channel and metaphor for this moving knowledge, with participatory media platforms like Twitter and YouTube being recent examples. Scrolls, books, newspapers, and television were earlier modes. Perhaps the most significant sensibility of modernity is movement, of goods services, money, information and people. An arc beyond 
the local creates formal and informal pathways between spaces. Transportation systems and technology increase not only the speed at which change takes place, but also the consciousness of change.

In thinking about time and learning, I made the decision to not make these method sessions into podcasts. I continue to use my phrase 'sonic sessions' to describe the genre. There was no RSS feed for a reason. [53] Podcasting is like a sonic direct debit: we set it and it arrives without too much thought.[54] I did not want the learning object to be pushed to students unconsciously, laying dormant and unheard on their hard drive. I wanted them to choose the time and place they would listen to the session. It also ensured an independently timed progression through the course. However, I mobilized many of the attractions of podcasting, including use a plurality of voices, views, accents and program lengths.

I also wanted the content to be mobile. Research is showing that students who are accessing podcasts are not listening on the move, but at home and on their computers. [55] However, my students did enjoy the time shifting capacities of learning. Mobility has been studied in methodical and innovative ways by John Urry[56] and his research colleagues at CeMoRe, the Centre for Mobility Research at the University of Lancaster. Their paradigmatic investigations have tempered mobile connectivity with mobile failure, and aligned transportation and communication systems. When placing attention on how people, money and ideas move, mobility becomes a new marker of class and power. Those who hold power have a choice to move. Those who lack power are immobile. Therefore, an easy acceptance of mobile learning needs to be questioned. For the part time, distance education students, it was a valuable service to create mobile content and they did use it.

Ironically, this propensity and capacity to slow learning is based on the speed of technological change - in both hardware and software - during the last two years. There has never been a better time to experiment with sound, education and research methods. Yet through all this planning and research into sound and education, the question is how students engage with this way of teaching and learning.

\section{The Movement}

There were some difficult transitions for the students to negotiate. As Henry Jenkins has stated, "Every risk you take comes with a price." [57] Moving into this new way of teaching methods, some of the scholars who had passed directly from the undergraduate to postgraduate program were inexperienced in online education and had to be scaffolded into participation utilizing asynchronous teaching and learning methods. I took Amanda Berry's advice.

As teacher educators begin to move away from traditional models of teaching about teaching to explore new ways of working with their students, many begin to experience feelings of self-doubt and uncertainty about how to proceed in this task.[58]

When challenges emerge, it is important to remember the caliber of the preparation undertaken and the reasons for choosing this alternative mode of teaching and learning. While confidence is important, it is also necessary to watch, listen and hear what students are telling us.[59] I addressed problems early in the program directly with the students. To assist staff in modeling the new method of teaching, I conducted the first two sessions, providing the introduction and the session on Unobtrusive Research Methods. The response was superb. However. there were lurkers and I wanted to prompt them into a more active engagement with the materials.

T.M.Brabazon@brighton.ac.uk [mailto:T.M.Brabazon@brighton.ac.uk]

Sent: Sat 18/10/2008 07:16

To: "MJMO1"

Subject: Welcome to Week Three!!: MJMO1

Good Morning Practising Media Researchers!

Now guys - we're about to enter WEEK THREE of practicing media research. Make sure that you've heard the first two sonic sessions - done that reading - left a few comments and posts (big shout out to the guys who have been keeping me company!) and are READY TO GO into Visual Research Methods with our Julie Doyle! She is amazing - and it is a really beautiful sonic session. I listen to it all the time...

I'll be still lurking - so if you are catching up and leaving messages - we'll keep those parts of the course alive. That's the advantage of Asynchronous methods. 
I'll also be guiding you through the assignments in the next couple of weeks. :) NO STRESS. I've been getting worried emails. NO STRESS - PROMISE. Really easy - and I'll guide you through them...

But remember guys - the great advantage of teaching methods in this way is that we don't have these dry and boring (!!!) discussions about methods (zzzzzzzzzzzzzzzzz). You will have access to these sonic sessions throughout the year(s), including during the writing of your dissertation. So you can keep returning to the ideas. All cool. You can work out what you think in stages - and apply what is useful...

Therefore, (and some of you have worked it out) the great advantage of this busy discussion forum is that we're creating a collective journal as we engage with each method. So you're helping each other to work out the strengths, weakness and problems of each method. I re-read the messages yesterday, and your insights are AMAZING. So remember to look back on what we've said about these methods when you come to write up assignments and do your dissertation. Andy and Venessa you are doing some amazing work with URM and how you create a research question. Amazing.

But all of you are brilliant and really innovative people. And you're sharing great insights with each other. So if you haven't quite left your mark on the discussion forum - don't think it's too late and don't be frightened. Just have a go. It's a very supportive environment. So we'll all work together to create a great collective journal (and journey) through methods! Your ideas matter - a lot.

Have a lovely weekend. Drop me an email and say hi.

\section{T XXX}

I also worked with individual students, particularly those who moved from the undergraduate to the postgraduate degree and needed a more detailed explanation for the transformation in how methods would be taught.

\section{Brabazon Tara}

Sent: Fri 17/10/2008 03:45

To:

\section{Subject: Checking in!!}

\section{Hey XXXX -}

Just doing my two weekly check in :) Hope you are well. It's given me so much happiness to see you every week - I cannot tell you. You are a real light in the darkness :)

The quick conversation I was going to have with you was over methods! I know for you - and XXXX - the new way of teaching is a bit 'hoollleeee hellllll' what's going on here... I realized yesterday - while doing our reading for Media Literacies by the way!!! - that I never explained to you WHY it is being taught this way. So this may help to explain and show what's going on - and why it won't bite ya!

The teaching of methods in this way - my idea originally came from MEL. We were in one of those course boards a couple of years ago. Mel reported a series of problems with how methods were taught for the undergraduates. The things I remember were

1. students didn't come to the class

2. when students needed the methods for their dissertation - they couldn't remember them (!!) / or weren't there in the first place

3. the discussions were dry - they couldn't see how the methods were actually used

4. students didn't have much choice in methods - either discourse analysis or focus groups ;)

5. students were seriously bored by methods. Not a pleasant class.

So - when I came to think about how to construct the program, I wanted to solve these problems in a fresh and new way. My priority - as you can see by the title - is to show students how to practice media research. I didn't want to create a disconnection between methods and applications. But for the masters - I wanted to create a series of seamless relationships. Students would see how the methods operate - and apply them to their own work RIGHT AT THE START.

Also, I wanted to widen the range of approaches. Particularly from a humanities side, you guys didn't see some of the most common methods in terms of action research, interdisciplinary popular cultural approaches, oral history, Unobtrusive 
Research Methods - so I wanted to make sure that they were there as well.

And the key - I wanted the students to be able to return to the sessions on methods throughout the masters. Whenever they needed them - I wanted them there. Also - I wanted a record of students' engagement with them - like a collective journal through the method... When students needed an approach - they could re-hear a session and look at the response from other students...

That's why I struck upon using the sonic sessions. Sound is an intimate medium. It can create a connection between ideas, and an intimacy between speaker and listener. Podcasts are called the medium of the whisper, which I like. But students could pause, rewind, fast forward and have a think. Then the guided questions through the forum would help them through the key issues of applying these ideas...

Hope that helps a bit. It just struck me yesterday that I never explained to you WHY I was using this method. And poor XXXX was thinking - this is weird. Why is this all online???? So I thought I'd give you the rationale - so you can see what we're doing and why:)

Now let me know if I can do anything at all. I'm hearing that you're doing fabulously well :) And obviously the other students love ya like we all do. Let me know if I can do anything - and don't be worried about the new teaching environment. It is like a collective journal. Everyone goes through the methods and helps each other. That's all. No marks on it - nothing decided - just people from all over the world working together :)

Bit better???

$\mathrm{TXXX}$

The reply suggested that the explanation did work. In future presentations of this module, I will explain the reasons for this way of teaching in greater depth, rather than allowing my rationale to be assumed rather than expressed.

\section{XXXX}

Sent: Sat 18/10/2008 10:13

To: Brabazon Tara

Subject: Re: Checking in!!

Helloooooo,

Aw thanks for emailing me about this - I really appreciate it! The reasoning behind it makes much more sense now I've read through it and had a think about it, and I think that doing the module online is actually a good idea, even though I'm finding it a bit freaky! You're totally right about the fact that students didn't go to the lessons last year, and the discussion board/ sonic sessions (which I really like) will be a brill resource come assignment time.

Sorry that I've not been more active on the discussion board. I won't bore you with my excuses, but hopefully from next week onwards I'll have a bigger input! Although I am still a bit intimidated by some peoples' wonderfully intelligent answers - everyone is very eloquent in their responses (I wish I was!).

Anyway, all is good. Really enjoying things so far, and loving our Monday sessions! :-)

See you soon,

Through these early teething problems, advantages emerged very quickly. The on and off campus students had an opportunity to converse and debate with others. English as second language scholars could orient themselves into the university community by repeatedly hearing sessions rather than being locked into a single lecture and seminar in real time. However, for domestic students who had experienced the other version of the undergraduate methods module, the difference in our mode was not only productive, but revelatory.

Abi: At first I thought wooow it's online. Technology. But I found it made you learn more, made you interact more, and be more active, I think, learning. I learnt more for it being on the internet because I had to actively - I could do it any time of the day cause doing it at $9 \mathrm{am}$ in the morning, when we used to do it before, it was quite hard to motivate yourself at that time of the morning to learn that stuff. Just being able to sit at home and do it at your own pace and sort of ... it just made it clearer, I think. You have to be more active. Active learning, eh?

The other advantage of asynchronous delivery that I was not expecting is that a few students fell behind the 
teaching schedule in the first couple of weeks. While we did run an orientation session, we probably needed to ensure that the students were more organized in their work patterns. They were enjoying their new program, new friends and new city too much. However, the advantage of the asynchronous delivery is that when I became aware that they needed to engage in greater depth from the first two weeks, they were able to catch up to the more disciplined scholars and continue their work. Also, hearing actually existing case studies of how research methods operate in scholarly life was as appropriate as I hoped it would be, introducing students to a range of staff and giving them a stream of contacts. For journalism and public relations students in particular, the applications of research methods connected their past experiences in the media with their current projects with the media.

Students started to enjoy and understand the diverse ways in which sound was being used in the Masters. I still deployed short sonic sessions in the other modules, but with diverse goals. The use of sound in discussing assignments seemed to help as students heard the same information from a study guide in a different way. Many students put the sonic sessions on a loop while they were writing or drafting their papers and projects, to keep themselves on track. Their movement in thinking was also a movement in staff thinking. We all started to consider with much more reflection and consideration which medium suited a research project and learning moment. The staff did well, considering the newness of the mode of teaching. For research inactive staff, it formed a pivotal moment to reconnect them with thinking, reading and writing. Particularly, considering the short notice at which many of the staff were asked to contribute, I was grateful for their generosity. However, it was amongst the students that the magic started.

\title{
4. The Magic
}

After the first week of teaching, it became clear that something extraordinary was happening amongst the students. Firstly, they started to independently record all their seminars and logged them into a private portal.

\author{
Our site is ready! \\ To members of MA Creative Media
}

\begin{abstract}
Hey everyone! Just a quick note to let you know that the site is ready and up. You can start using it immediately but you will have to register first. I am slowly uploading the recordings from the seminar as I type this so everything I have should be up by tomorrow. I need some volunteers to record the seminars I do not attend. Anyone? Please? So far I have recruited the lovely Lucy for Mediating the Environment (if I remember well) but I need more so we can cover everything.
\end{abstract}

I have a recorder we can all use and maybe Tara can lend us hers too if there is a clash or the exchange of the recorder failed somewhere along the way (shit happens, ya know!).

\begin{abstract}
Anyway, head over to www.macreativemedia.co.uk and register yourself (there is a link to register under the login box) so you can access the site. I will make sure to upgrade your account to "Editor" so you can post anything you want also. Feel free to grab the RSS feed if you are into the whole RSS scene but you may have problems with it since the site is password protected. I am looking into a notification feature so we can all be emailed when there's fresh content added on the site.
\end{abstract}

That's all I can think of right now.

I hope you're enjoying your hump day (this always sounds dirty to me).

Take care!

Yanni $\mathrm{xx}$

The other students all followed Yanni and started to record everything. We added library sessions and comments to the portal. Everyone gained from Yanni's commitment but the distance education students became the biggest beneficiaries of his work.

\section{Sent: Thu 23/10/2008 00:07 \\ To: Brabazon Tara \\ Subject: RE: bloggity blog}

Bugger.... ok. Sorry, I got sucked into a little vortex of analysis with $\mathrm{mX}$ there (I do it in life also :)

Next post going up today. Thanks for your help and guidance. I really don't want to be the special needs student! 
Am poking around Yanni's site - HURRRRRAH for hearing you all!!! He’s a legend!!!

Remarkably, they continued to record sessions all year, right until the final week of seminars.

Yanni

Sent: Fri 15/05/2009 22:00

To:

Cc:

Subject: Approaching the end of term!

Hello to everyone!

Right, there are a couple of rough weeks ahead filled with deadlines and general (sometimes weather induced) insanity so I thought I'd try to see if I can keep/put things in place for you to help out. I keep asking myself when will the weather realize that it's mid-May and act appropriately. Of course, when the sun finally comes out I start sneezing and generally become an overflowing snot machine and curse all the Gods of Olympus as I try to wheeze some oxygen into my system and up to my brain. Hurrah for hay fever...

Anyway, back to the point. This is a notification email to let you all know that I finally had some time today to convert and upload this week's seminar recordings. With the exception of Julia's module for which we have one last seminar next week, these are the last recorded sessions for this semester. I am sending this update to all of you so you know everything is up to date on the website ( http://macreativemedia.co.uk ) and you can have a listen before completing your assignments. Keep in mind that all the recordings from the first semester are still online as well. I will keep those up until at least the end of September so we all have access to them. They might be useful when working on your dissertations.

That's all from me for now. Best of luck to all of you on your assignments! Keep it together and see you soon!

Yanni $\mathrm{xx}$

The distance education students appreciated everyone's work and again thanked Yanni for all his efforts.

Sent: Sat 16/05/2009 05:32

To:

Subject: RE: Approaching the end of term!

I'd just like to second that sentiment. Yanni's efforts have really made the difference for this distance student. I listen to you all on my daily commute, and really feel a part of the action.

w00t!

$\mathrm{x}$

This idea was completely derived from the students, aligning the computer science expertise from Yanni with the design experience of another and the educational interests of others. They also started to independently experiment with sound and recording devices. Basically, they started to record everything. They asked me to teach them how to use a range of mixing software.

There were other surprises and moments of magic. Oral history, which I thought would be a minor research method, became the method that most of them chose to specialize on and with for their research. Significantly, and startlingly, the conventional problems of creative-led or practice-led research, captured best through the disconnection of artefact and exegesis, never appeared in any of the student's research. They seemed to - naturally it appeared - understand how to align creative work, method and the configuration of an exegesis. There are probably many causes for this ease of movement between platforms but one reason must be that they were taught methods in a way that was applicable, challenging, malleable and living, rather than dry, abstract and unused. There was no gap between theory and production, analysis and practice.

On the basis of our experimentation with methods, the entire group aligned sonic media and education. The year became punctuated by sound, aurality and orality. What Francisco Lopez described as "a 'blind' listening" [60] started to emerge. The assignments from the methods module were remarkable. As an example, one of my students offered an experiment in oral history methods, recording the same testimony in three ways - sound only, sound and vision, vision only with close-captioning - to investigate the different type of evidence and interpretation that could be gained from the diverse sources. Another aligned form and content by interviewing the manager of the 
North-West sound archive. He researched oral histories by interviewing a curator of a local sound archive. Form and content blended through oral history and sonic media.

Our academic culture became more audible and created space for interpretation, silence, abstraction and analysis. While Paul Carter stated that "listening becomes a cultural work where the ground rules are not established,"[61] he also realized that active listening is situated in cultural, historical and social environments. It provides an opportunity to create "new symbols and word senses." [62] The student innovations triggered a feedback loop to staff who also became inspired by the diversity, range and quality of assignments. As I reviewed the first year of the MA Creative Media, I noted that students and staff had developed a sonic media and auditory cultures portfolio. While I had always used popular music, oral history and recorded speeches as punctuation in both my teaching and research, we were able to extend far beyond these conventional usages. Our project commenced with a desire to solve problems in the way in which we taught research methods. The teaching-led research literature and media literacy theory helped us, as did transferable learning object theories.

Through the year, and inspired by the students' enthusiasm for diverse sounds and voices in our Masters, I continued to work with them, asking how I could help them through developing time and space-shifting genres for sonic education. I started to conduct specialist micro-interviews on particular topics that can be used for a specific goal in a lecture theater or the more intimate environment of a seminar room and then transferred through the Web to wider and different international usage. [63] Students listened to these micro-teaching moments and then commenced their seminar discussion. They could then return to this micro-interview outside the seminar. This new genre was based on a simple idea, asking one question and receiving one answer. Of less than two minutes, they introduced new voices into teaching spaces and sonic learning objects to augment print-based texts and directed students to alternative learning experiences. While I started to use this mode in all my undergraduate and postgraduate teaching, it had great success in the Masters. Students were reading Professor Steve Redhead's "The Art of the Accident"[64] to understand the relationship between terrorism and cities. It was incredibly useful for students to hear how ideas can be transposed into publications and research deployed in new contexts. [65] Through the mobility of sonic media, expertise could be brought into the teaching and learning space, while also enlarging the genres of online learning objects and online learning resources

Again, this innovation in the use of sonic media provided another opportunity for staff development. Staff who may have been apprehensive or fearful of constructing a full Practising Media Research session can be scaffolded into this longer recording. The informality of one question and one answer, taking less than two minutes, is a way to lift the confidence of staff in deploying new media platforms, while also increasing the resources available to students. It is another way to enable research inactive staff to express an idea or disseminate works in progress.

I also developed a liminal length of presentation between the short sonic sessions and the longer offering for Practising Media Research. Being of less than ten minutes, they formed a series of public education sonic sessions, held on the Internet Archive with the wraparound from my website. The topics included education, libraries, popular culture, and social justice.[66] The Sonic Lab from my website[67] created an opportunity to share these experiments with both colleagues and students, and in the future will present an important opportunity to disseminate the MA students' research in sonic form. My goal is to ensure that each student produces a sonic session from their MA dissertation to not only disseminate their research but form a show reel to enable their future employment.

A recently released book by Jeff Jarvis asked a provocative question in its title: "What Would Google Do?" Probably, my method of teaching research methods would suit the supercorporation. It solved a problem. It opened students to a range of voices, views and resources. It also inspired them to think that they could take their voice, views and resources and create independent research. It was mayhem. The time scale of development, the lack of equipment and the clunky portal did not bode well. Yet we survived. The students thrived and succeeded and we have built on this first experiment in new and fascinating ways. This mayhem with methods embodied Frauke Behrendt's reading of our time.

It is not only the old technology of the computer and the Internet moving to new social and geographic context by becoming mobile. Something new is emerging from this, for which a lot of new terminology has been tried out, but only little appropriate metaphors have been found so far.[68]

Perhaps attention to the dynamism of sonic platforms, rather than similes and metaphors of the Internet, may be more productive in tracking the changing relationships between media and education. Staff and students transformed universities into sonic laboratories for hearing, listening and thinking. While our experiments continue, we have realized that fewer media may create more meaning. 


\section{Endnotes}

1. Sonic media, as a phrase, has been used intentionally through this paper as it moves fluidly between the categories of high and popular culture. It maintains relationships with acoustic studies, digital and internet studies and audio and auditory cultures.

2. Cheryl Bluestone realized that "despite its importance, even at the graduate level, students tend to perceive research methods and statistics coursework as uninteresting and difficult," from "Infusing active learning into the research methods unit," College Teaching, Vol. 55, No. 3, 2007: 91.

3. I also acknowledge the inspiration of Susan Gibson and Bonnie Skaalid in the construction of this article. Gibson and Skaalid stated that "unless teachers are exposed to new ways of thinking about their practice and the role that computers can play in their changed practice, they will continue to use computers as an add-on to the ways they have traditionally taught," from "Teacher professional development to promote constructivist uses of the internet: a study of one graduate-level course," Journal of Technology and Teacher Education, Vol. 12, No. 4, 2004:579.

4. Paul Carter stated that "active listening is not simply psychological jargon. In the context of 'hearing cultures' it conjures up historical, cultural, or social situations in which listening surfaces as a device for dreaming new symbols and word senses. As these arise dialogically, in the back-and-forth of mutual (mis-)understanding they have the capacity to ground communication differently ... the cultural work done on such occasions is far from trivial. Usually precipitated in circumstances of an imminent loss of personal and collective identity, its echoic poetics is both tactical and profoundly political," from P. Carter, "Ambiguous traces, mishearing, and auditory space," in V. Erlmann (ed.), Hearing Cultures, (Oxford, Berg, 2005)

5. D. Gauntlett, "Media Studies 2.0," Theory.org.uk , http://www.theory.org.uk/mediastudies2.htm , 24 March 2007

6. W. Merrin, "The Revolution has already taken place," Media Studies 2.0 Forum, http://twopointzeroforum. blogspot.com/2007/03/revolution-has-already-takenplace.html, 3 March 2007.

7. R. Quin, A genealogy of Media Studies. The Australian Educational Researcher, 30, Vol. 1, 2003, pp. 101-122.

8. The Creativity CELT (Centre for Excellence in Learning and Teaching) was present at the University of Brighton, http://staffcentral.brighton.ac.uk/clt/ projects/CETLs.htm\#cre

9. Asynchronous media platforms were chosen to ensure that students could fit the modules into their work and family commitments. Also, distance education students were considered at the start of course development. They were not an inconvenient addition to the on campus mode. The full course was available in both on and off campus modes from the launch of its program. Therefore, there was a different motivation to distance education when compared to Matthew Roberts, who stated that "it all started with a scheduling conflict ... one student let me know that she would need to miss our research methods class the coming week. As hands popped up around the room I realized I would be missing almost a third of my class. Unfortunately, they were going to miss crucial lectures on measures of significant and measures of association, without which they could be considerably lost when it came to the semester research paper," from "Adventures in podcasting," PS: Political Science \& Politics, Vol. 41, No.3, July 2008.

10. I particularly want to note the literacies series that, although resident at Routledge, was commenced by the Bill Cope and Mary Kalantzis edited collection, Multiliteracies , (Melbourne: Macmillan, 2000). Influential texts in Routledge's series include Gail Hawisher and Cynthia Selfe, Global Literacies and the World-Wide Web (London: Routledge, 2000), Gunther Kress's Literacy in the New Media Age, (London: Routledge, 2003), Ilana Snyder (ed.) Silicon Literacies , (London: Routledge, 2002) and David Barton, Mary Hamilton and Roz Ivanic edited collection, Situated Literacies, (London: Routledge, 2000)

11. Many of these influential materials are included throughout the piece, but I would particularly like to note Annette Lamb and Larry Johnson's “Podcasting in the school library, part 2: creating powerful podcasts with your students," Teacher Librarian, Vol. 34, No. 4, April 2007. In this article, they stressed the ease of construction as a way "to promote technology to reluctant teachers," p. 61. They also stressed the importance of a standard format, particularly using music. Their advice was followed. They also argued for the diversity of possible genres, including book reviews, collaborative projects, promotion of events, interviews and original sonic productions. Through the year, I have experimented with this diversity of material for future use in teaching and learning. Please refer to www.brabazon.net/soniclab .

12. My experience through the MA Creative Media in terms of distance learning was also confirmed in Muhammad Imran Yousuf's "Effectiveness of mobile learning in distance education," Turkish Online Journal of Distance Education, Vol. 8, No. 4, October 2007, http://tojde.anadolu.edu.tr/tojde28/pdf/article_9.pdf

13. C. Murrell, "Interactive student podcasting: the emerging technology of choice," in A.Oosterman, A. Cocker (eds.), Journalism Downunder: the future of the media in the digital age. Proceedings of the $2 \mathrm{nd}$ joint JEANZ/JEA Conference, School of Communication 
Studies, AUT University, Auckland, New Zealand, 2006, http://artsweb.aut.ac.nz/journalism_conference/docs/ paper-Murrell.doc , p. 1

14. Anthony Chan and Catherine McLoughlin, "Everyone's learning with podcasting: a Charles Sturt University experience," Proceedings of the 23rd annual Ascilite conference, p. 111

15. While application was a focus of my work, it was not an example of problem-based instruction or problembased learning as was introduced by Margaret Greenwald in teaching graduate research methods. I certainly note her corrective that "a problem-based approach to teaching research methods allows the instructor to build directly on the students' current level of knowledge in clinical diagnosis and treatment and to help students to extend clinical questions into research questions," from "Teaching research methods in communication disorders," Communication Disorders Quarterly , Vol. 27, No. 32, 2003:179.

16. J. Maness, "Library 2.0 theory" Webology, Vol. 3, No. 2, June 2006, http://webology.ir/2006/v3n2/a25.html

17. I am not undermining the seriousness of this rushed preparation. Frank Troha is absolutely correct: "A successful-learning or blended learning initiative requires careful project planning, solid instructional design, the development of all instructional components based on an approved design document, ongoing attention to project management issues ... varies formative evaluations prior to launch, deployment of the learning and ongoing evaluation and maintenance of the learning system," from "Ensuring e-learning success: six simple tips for initiative leaders," USDLA Journal , December 2002:15.

18. S. Junaidu and J. Al-Ghamdi realized that "before beginning course development, online course developers should have a clear understanding of their target audience, the learners," from "Tips for developing media-rich online courses," USDLA Journal, December 2002:18. Junaidu and Al-Ghamdi particularly stressed motivation, knowledge, language level and computer literacy.

19. N. Durbridge, The role of technology in distance education, (Kent: Croom Helm, 1984)

20. D.J. Power, "The use of audio in distance education, in S. Timmers (ed.) Training needs in the use of media for distance education, (Singapore: Asian Mass Communication Research and Information Centre, 1990)

21. M. Lee and A. Chan, "Reducing the effects of isolation and promoting inclusivity for distance learners through podcasting," Turkish Online Journal of Distance Education , Vol. 8, No. 1, January 2007, http://www.eric.ed.gov/ERICDocs/data/ericdocs2sql/ content_storage_01/0000019b/80/27/fa/95.pdf .
22. I use the phrase 'sonic sessions' to signify a distinction from both podcasts and online lectures. By deploying a distinctive nomenclature, I am attempting to show that a sonic session is written, recorded and structured differently from a lecture that has been recorded.

23. D. Kahn, Wireless Imagination, (Cambridge: MIT Press, 1994), p. 4

24. K. Jensen, "Sounding the media," Nordicom Review, Vol. 27, 2006, p. 7

25. S. Brittain, P. Glowacki, J. Van Ittersum, L. Johnson, "Podcasting lectures," Educause Quarterly, Number 3, 2006, p. 28

26. C. Windham, Confessions of a podcast junkie: a student perspective. Educase , May/June 2007, http:// connect.educause.edu/Library/EDUCAUSE+Review/ ConfessionsofaPodcastJunk/39405

27. M. Norquay, "Writing for the ear," in L. Burge, M. Norquay and J. Roberts (eds.), Listening to learn , (Ontario: Ontario Institute for Studies in education, 1987), p. 11.

28. G. Berg, The British Invasion. WebNet Journal, January-March, 2001, 5-6

29. A.W. Bates, Technology for distance education: A 10 -year perspective, from A. Tait (ed.) Key issues in open learning - a reader: An anthology from the journal 'Open learning' 1986-1992, (Harlow: Longman, 1993), pp. 241-265

30. ibid. , p. 242

31. Allison Cavanagh realized how rarely this point is actualized. She stated that "the idea of a radical schism between new media, in particular the internet, and prior forms of media is a common trope of the field," from "Contesting Media History," Westminster Papers in Communication and Culture, Vol. 4, No. 4, 2007, p. 6

32. "Podcasting: a teaching with technology white paper," Office of Technology for Education \& Eberly Center for Teaching Excellence, Carnegie Mellon University, June 4, 2007

33. Y. Belanger, Duke iPod first year final evaluation Report, (Durham: Duke University, 2005), http://cit. duke.edu/pdf/ipod_initiative_04_05.pdf

34. B. Read, "Lectures on the go," Chronicle of higher education , 52 (10), 2005, http://chronicle.com/ weekly/v52/i10/10a03901.htm

35. S. Earp, Y. Belanger, L. O'Brien, Duke digital initiative end of year report. Durham: Duke University, 2006, http://www.duke.edu/ddi/pdf/ddi_exec_report _overview_05_06.pdf 
36. Office of Technology for Education \& Eberly Center for Teaching Excellence, Podcasting: a teaching with technology white paper. Pittsburgh: Carnegie Mellon University, June 4, 2007, http://connect.educause.edu/ files/CMU_Podcasting_Jun07.pdf

37. ibid.

38. ibid. , p. 3

39. T. Brabazon, "Socrates in earpods: the ipodification of education. Fast Capitalism , 2 (1), 2006, http://www. uta.edu/huma/agger/fastcapitalism/2_1/brabazon.htm

40. ibid.

41. I note David Millard and Martin Ross's corrective that "Web 2.0 is not a system, nor even a class of systems," from "Web 2.0: hypertext by any other name," HT’06, Odense Denmark, August 22-26 2006, p. 28

42. Jean Burgess tracked the amateurization of photography and the domestication of personal computing as a form of "Vernacular creativity and new media," from her $\mathrm{PhD}$ thesis at the Queensland University of Technology, 2007.

43. P. Meng, Podcasting gains an important foothold among US adult online population, according to Nielsen//Netratings, 2006, http://www.nielsen-netratings. com/news.jsp

44. A. Chan and C. McLoughlin, Everyone's learning with podcasting: a Charles Sturt University experience. In: Proceedings of the $23 \mathrm{rd}$ annual Ascilite conference Sydney, Australia , 2006, http://www.ascilite.org.au/ conferences/sydney06/proceeding/pdf_papers/p219. pdf

45. C. Windham, Confessions of a podcast junkie: a student perspective. Educase, May/June 2007, http:// connect.educause.edu/Library/EDUCAUSE+Review/ ConfessionsofaPodcastJunk/39405

46. C. Murrell, "Interactive student podcasting: the emerging technology of choice," in Allison Oosterman, Dr Alan Cocker eds., Journalism Downunder: the future of the media in the digital age. Proceedings of the 2nd joint JEANZ/JEA Conference, School of Communication Studies, AUT University, Auckland, New Zealand, 2006, http://artsweb.aut.ac.nz/journalism_ conference/docs/paper-Murrell.doc

47. Y. Zhao and G. Cziko found three conditions to be met for staff to enact professional development to use new platforms. Firstly, staff must believe it can meet higher level goals than other methods. Secondly, they must believe that it will not effect other higher learning goals. Finally, they must feel confident that they hold the ability and resources to use it. Please refer to Y. Zhao and G. Cziko, "Teacher adoption of technology: a perceptual control theory perspective," Journal of Technology and Teacher Education, Vol. 9, No. 1, 2001.
48. "Tara Brabazon talks with Julie Doyle about using sonic media to teach visuality," Internet Archive, http://www.archive.org/details/TaraBrabazonTalks ToJulieAboutUsingSonicMediaToTeachVisuality

49. A. Toffler, Powershift, (New York: Bantam, 1991), p. 459: http://www.scribd.com/doc/7000495/AlvinToffler-Power-Shift

50. J. Tomlinson, The culture of speed: the coming of immediacy, (London: Sage, 2007), p. 1

51. P. Virilio, Pure war ,(New York: Semiotext(e),1983), p.28

52. The forum was an integral part of this module. It is the component that I will work on in future years. The participation was strong - but uneven. There were - as always - lurkers and uneven participation from week to week. But through the semester, over 800 posts were recorded from the students in response to the structured questions I asked them. It also provided a great opportunity for students to engage each other regardless of their enrolled mode. However I do note Fei Gao and David Wong's fascinating work in "Student engagement in distance learning environments; a comparison of threaded discussion forums and text-focused Wikis" First Monday, Vol. 13, No. 1, January 2008, http://firstmonday.org/htbin/ cgiwrap/bin/ojs/index.php/fm/article/view/2018/1921. Their discussion of threaded discussion fora, text-based wikis generally and seedwikis in particular ( www. seedwiki.com ) is important. The direct engagement with particular portions of text is useful and I will investigate this potential in future offerings.

53. I was inspired by George Lorenzo, Diana Oblinger and Charles Dziuban's argument that "With all these choices, do we really know what we are doing, whether the information is valid, or how best to use it?" in "How choice, co-creation, and culture are changing what it means to be net savvy," Educause Quarterly, Vol. 30, No. 1, 2007, http://www.educause.edu/apps/ eq/eqm07/eqm0711.asp?bhcp=1. Therefore, my goal was to ensure that some choice, pauses and stops were introduced into the process of both finding learning materials and engaging with them.

54. A paper from the Office of Technology for Education \& Eberly Centre for Teaching Excellence at Carnegie Mellon University confirmed that "In general, it is safe to say that most students do not listen to each and every lecture podcast. Only $20 \%$ of students in the UW study listened to more than $75 \%$ of recorded lectures," from "Podcasting: a teaching with technology white paper," Office of Technology for Education \& Eberly Center for Teaching Excellence, Carnegie Mellon University, June 4, 2007

55. ibid. , p. 6

56. An example of this research includes John Urry's "The complexities of the global," published by the 
Department of Sociology, Lancaster University, Lancaster UK, http://www.comp.lancs.ac.uk/sociology/papers/urrycomplexities-global.pdf, July 2, 2004

57. H.Jenkins, "The warbetween effects and meaning," MIT, http://web.mit.edu/cms/faculty/WarEffectMeaning.htm

58. A. Berry, "Confidence and uncertainty in teaching about teaching," Australian Journal of Education, Vol. 48, No. 2, 2004, p. 152

59. Elizabeth Van Es and Miriam Gamoran Sherin argued that "teaching is a complex activity. In any given lesson, teachers need to attend to what students are doing and saying, how they are thinking about the subject matter, what analogies or representations to use to best convey important ideas, and what experiences to provide students to engage them in learning," from "Learning to notice: scaffolding new teachers' interpretations of classroom interactions," Journal of Technology and Teacher Education, Vol. 10, No. 4, 2002, p. 572

60. F. Lopez, "Profound listening and environment sound matter," in C. Cox and D. Warner (eds.), Audio Culture, (New York: Continuum, 2004), p. 82

61. P. Carter, "Ambiguous traces, mishearing, and auditory space," in V. Erlmann (ed.), Hearing Cultures , (Oxford: Berg, 2005), p. 44

62. ibid. , p. 45
63. While many of these sessions were recorded, two examples from Steve Redhead are "Art of the Accident," Internet Archive, http://www.archive.org/details/ ArtOfTheAccident and "Cities and Popular Music," http:// www.archive.org/details/CitiesAndPopularMusic

64. S. Redhead, "The art of the accident," Fast Capitalism , Vol. 2, No. 1, 2006, http://www.uta.edu/ huma/agger/fastcapitalism/2_1/redhead.html

65. T. Brabazon talks to S. Redhead, "Art of the Accident," Internet Archive, http://www.archive.org/ details/ArtOfTheAccident

66. Examples include T. Brabazon, "Analogue ways of thinking," Internet Archive, http://www.archive.org/ details/AnalogueWaysOfThinking and "Dust bowl democracy," Internet Archive, http://www.archive. org/details/AnalogueWaysOfThinking

67. Sonic Lab, Brabazon.net, http://www.brabazon. net/soniclab

68. F. Behrendt, "From calling a cloud to finding the missing track," Mobile Music Workshop, 2005, http:// www.viktoria.se/fal/events/mobilemusic/papers/ Behrendt_mmt05.pdf

\section{References}

Barton, D., M. Hamilton, and R. Ivanic, eds. 2000. Situated Literacies. London: Routledge.

Bates, A.W. 1993. “Technology for Distance Education: A 10-Year Perspective." Pp. 241-265 in Key Issues in Open Learning - a Reader: An Anthology from the Journal 'Open Learning' 19861992, edited by A. Tait. Harlow: Longman.

Behrendt, F. 2005. "From Alling a Cloud to Finding the Missing Track." Mobile Music Workshop 2005 ( http://www.viktoria. se/fal/events/mobilemusic/papers/Behrendt_mmt05.pdf).

Belanger, Y. 2005. Duke iPod First Year Final Evaluation Report. Durham: Duke University ( http://cit.duke.edu/pdf/ipod_initiative_04_05.pdf).

Bluestone, C. 2007. "Infusing Active Learning into the Research Methods Unit.” College Teaching Vol. 55 3:91-95.

Berg, G. 2001. “The British Invasion.” WebNet Journal January-March:5-6

Berry, A. 2004. "Confidence and Uncertainty in Teaching about Teaching." Australian Journal of Education Vol. 48, 2:149-165.

Brabazon, T. "Analogue Ways of Thinking." Internet Archive ( http:// www.archive.org/details/AnalogueWaysOfThinking).
----. "Dust Bowl Democracy." Internet Archive ( http://www. archive.org/details/AnalogueWaysOfThinking).

----. 2006. "Socrates in Earpods: the ipodification of Education." Fast Capitalism Vol. 2, 1 ( http://www.uta.edu/huma/agger/ fastcapitalism/2_1/brabazon.htm ).

----. Sonic Lab, Brabazon.net (www.brabazon.net/soniclab).

----. “Tara Brabazon Talks with Julie Doyle about Using Sonic Media to Teach Visuality." Internet Archive (http://www. archive.org/details/TaraBrabazonTalksToJulieDoyleAboutUsi ngSonicMediaToTeachVi suality).

Brabazon, T. and S. Redhead. "Cities and Popular Music." (http://www.archive.org/details/CitiesAndPopularMusic).

Brittain, S., P. Glowacki, J. Van Ittersum, and J. Johnson. 2006. "Podcasting Lectures." Educause Quarterly Number 3 ( http://www.educause.edu/EDUCAUSE\%2BQuarterly/ EDUCAUSEQuarterlyMagazineVolum/Podc astingLectures/157413).

Burgess, J. 2007. "Vernacular Creativity and New Media." Doctor of Philosophy, Queensland University of Technology. 
Carter, P. 2005. "Ambiguous Traces, Mishearing, and Auditory Space." Pp. 1-17 in Hearing Cultures, edited by Erlmann. Oxford: Berg.

Cavanagh, A. 2007. “Contesting Media History.” Pp. 6-13 in Westminster Papers in Communication and Culture. Vol. 4, No. 4 .

Chan, A. and C. McLoughlin. "Everyone's Learning with Podcasting: A Charles Sturt University Experience." Proceedings of the 23rd Annual Ascilite Conference (http:// www.ascilite.org.au/conferences/sydney06/proceeding/pdf_ papers/p219.pdf).

Cope, B. and M. Kalantzis, eds. 2000. Multiliteracies. Melbourne: Macmillan.

Creativity CETL (Centre for Excellence in Teaching and Learning). University of Brighton. 2010 ( http://staffcentral. brighton.ac.uk/clt/projects/CETLs.htm\#cre ).

Durbridge, N. 1984. The Role of Technology in Distance Education. Kent: Croom Helm.

Earp, S., Y. Belanger, and L. O’Brien. 2006. Duke Digital Initiative End of Year Report. Durham: Duke University. ( http://www. duke.edu/ddi/pdf/ddi_exec_report_overview_05_06.pdf).

Gao, F. and D. Wong. 2008. "Student Engagement in Distance Learning Environments: A Comparison of Threaded Discussion Forums and Text-Focused Wikis. " First Monday Vol. 13, No. 1, January 2008 ( http://firstmonday.org/htbin/cgiwrap/bin/ojs/ index.php/fm/article/view/2018/1921).

Gauntlett, D. "Media Studies 2.0.” Theory.org.uk March 24, 2007 ( http://www.theory.org.uk/mediastudies2.htm ).

Greenwald, M. 2003. "Teaching Research Methods in Communication Disorders." Communication Disorders Quarterly Vol. 27, No. 32:176-179.

Gibson, S. and B. Skaalid. 2004. "Teacher Professional Development to Promote Constructivist Uses of the Internet: A Study of One Graduate-Level Course." Journal of Technology and Teacher Education Vol. 12, No. 4:577-592.

Hawisher, G. and C. Selfe. 2000. Global Literacies and the WorldWide Web. London: Routledge.

Jenkins, H. "The War Between Effects and Meaning." MIT (http://web.mit.edu/cms/faculty/WarEffectMeaning.htm).

Jensen, K. "Sounding the Media." 2006. Nordicom Review Vol. 27:7-33.

Kahn, D. 1994. Wireless Imagination. Cambridge: MIT Press.

Kress, G. 2003. Literacy in the New Media Age. London: Routledge.

Lamb, A. and L. Johnson. 2007. "Podcasting in the School Library, part 2: Creating Powerful Podcasts with Your Students." Teacher Librarian Vol. 34, No. 4, April: 54-57.
Lee, M. and A. Chan. 2007. "Reducing the Effects of Isolation and Promoting Inclusivity for Distance Learners through Podcasting." Turkish Online Journal of Distance Education Vol. 8, No. 1, January. ( http://www.eric.ed.gov/ERICDocs/ data/ericdocs2sql/content_storage_01/0000019b/80/27/ fa/95.pdf).

Lopez, F. 2004. "Profound Listening and Environment Sound Matter." Audio Culture, edited by C. Cox and D. Warner. New York: Continuum.

Lorenzo, G., D. Oblinger, and C. Dziuban. 2007. "How Choice, Co-Creation, and Culture are Changing What it Means to Be Net Savvy." Educause Quarterly Vol. 30, No. 1 ( http://www. educause.edu/apps/eq/eqm07/eqm0711.asp?bhcp=1) .

Meng, P. 2006. "Podcasting Gains an Important Foothold Among US Adult Online Population." Nielsen//Netratings ( http://www.nielsen-netratings.com/news.jsp ).

Merrin, W. 2007. "The Revolution has Already Taken Place." Media Studies 2.0 Forum March 3, 2007 ( http://twopointzeroforum.blogspot.com/2007/03/revolution-has-already-taken-place.html).

Millard, D. and M. Ross. 2006. "Web 2.0: Hypertext by Any Other Name." HT’06, Odense Denmark, August 22-26

Miller, P. 2006. “Coming Together around Library 2.0.” D-Lib Magazine Vol. 12, No. 4, April 2006 ( http://dlib.org/dlib/ april06/miller/04miller.html).

Murrell, C. 2006. "Interactive Student Podcasting: The Emerging Technology of Choice.” Journalism Downunder: The Future of the Media in the Digital Age. Proceedings of the 2nd Joint JEANZ/JEA Conference, School of Communication Studies, edited by A. Oosterman and A. Cocker. AUT University, Auckland, New Zealand, 2006 ( http://artsweb.aut.ac.nz/ journalism_conference/docs/paper-Murrell.doc).

Norquay, M. 1987. “Writing For the Ear.” Pp. 1-11 in Listening to Learn, edited by L. Burge, M. Norquay, and J. Roberts. Ontario: Ontario Institute for Studies in Education.

Office of Technology for Education and Eberly Center for Teaching Excellence. 2007. "Podcasting: A Teaching with Technology White Paper.” Pittsburg: Carnegie Mellon University, June 4, 2007 ( http://connect.educause.edu/files/ CMU_Podcasting_Jun07.pdf).

Power, D.J. 1990. "The Use of Audio in Distance Education." Pp. 1-15 in Training Needs in the Use of Media for Distance Education, edited by S. Timmers. Singapore: Asian Mass Communication Research and Information Centre, 1990 ( http://www.scribd.com/doc/27071578/The-Use-of-Audioin-Distance-Education-Daniel-J-Power ).

Quin, R. 2003. "A Genealogy of Media Studies." The Australian Educational Researcher 30, vol. 1: 101-122.

Read, B. 2005. "Lectures on the Go." Chronicle of Higher Education Vol. 52, No. 10, 2005 ( http://chronicle.com/ weekly/v52/i10/10a03901.htm ). 
Redhead, S. 2006. “The Art of the Accident." Fast Capitalism Vol. 2, No. 1, 2006 ( http://www.uta.edu/huma/agger/fastcapitalism/2_1/redhead.html ).

Roberts, M. 2008. "Adventures in Podcasting." PS: Political Science and Politics, Vol. 41, No.3: 585-593.

Snyder, I., ed. 2002 Silicon Literacies. London: Routledge.

Toffler, A. 1991. Powershift. New York: Bantam. ( http://www. scribd.com/doc/7000495/Alvin-Toffler-Power-Shift ).

Tomlinson, J. 2007. The Culture of Speed: The Coming of Immediacy. London: Sage.

Troha, F. 2002. "Ensuring E-Learning Success: Six Simple Tips for Initiative Leaders." USDLA Journal December 2002 ( http:// www.usdla.org/html/journal/DEC02_Issue/article02.html).

Urry, J. 2004. "The Complexities of the Global.” The Department of Sociology, Lancaster University, Lancaster :UK July 2, 2004 ( http://www.comp.lancs.ac.uk/sociology/papers/urry-complexities-global.pdf).
Van E. and Sherin M. Gamoran. 2002. "Learning to Notice: Scaffolding New Teachers' Interpretations of Classroom Interactions." Pp. 571-596 in Journal of Technology and Teacher Education, vol. 10, No. 4.

Virilio, P. 1983. Pure War. New York: Semiotext(e).

Windham, C. 2007. "Confessions of a Podcast Junkie: A Student Perspective.” Educase May/June, 2007 ( http:// connect.educause.edu/Library/EDUCAUSE+Review/ ConfessionsofaPodcastJunk/39405).

Yousuf, M.I. 2007. "Effectiveness of Mobile Learning in Distance Education." Turkish Online Journal of Distance Education, Vol. 8, No. 4, October 2007 ( http://tojde.anadolu.edu.tr/ tojde28/pdf/article_9.pdf).

Zhao, Y. and G. Cziko. 2001. "Teacher Adoption of Technology: A Perceptual Control Theory Perspective." Journal of Technology and Teacher Education Vol. 9, No. 1, 2001. 